\title{
The Triad: Organizational Cultural Values, Practices and Strong Social Intra-Firm Networks
}

\author{
Faiza Khoja \\ University of Houston-Downtown • Houston, Texas
}

\section{Abstract}

The primary purpose of this research paper is to demonstrate the role, strong organizational culture plays in transforming a loosely connected organization to one with strong ties. The results of this study indicate that business units are likely to get assistance from other sister business units to accomplish tasks in a timely manner and to be innovative. Cultural practices, such as open communication and rewards incentivize units sufficiently to do so. It is found that cooperative values indigenously motivate units to develop strong networks and do not require the added inducement of collective rewards or open communication, as these practices seem to be resonant in values of cooperation.

\section{The Relationship between Organizational Cultural Values, Practices and Strong Social Intra-firm Networks}

In the past decade, strategists have studied the pervasive phenomenon of social networks or social relationships at various levels of analysis both within and outside the organization (e.g. Ahuja, 2000; Brass, Galaskiewicz, Greve, \& Tsai, 2004; Gulati, 1998; Gulati \& Singh, 1998; Hansen, 1999; Kraatz, 1998; Nohria \& Eccles, 1992; Tsai \& Ghoshal, 1998; Tsai, 2000 etc.). In this study, intra-firm or intra-organizational networks are analyzed, which allows units within an organization to develop new knowledge while cultivating existing know-how (Khoja \& Maranville, 2009; Tsai \& Ghoshal, 1998). Intra-firm or intra-organizational networks are defined as 'a set of relationships among business units of the same legal firm that interact with each other to exchange resources, information, and/or services' (Achrol \& Kotler, 1999).

Most of the research studies, to date, have primarily analyzed the characteristics of intra-firm networks or lateral linkages, ${ }^{1}$ such as network centrality, ${ }^{2}$ structural holes, ${ }^{3}$ tie-strength, ${ }^{4}$ network size, ${ }^{5}$ and network density ${ }^{6}$ to assess performance, innovation, resource (knowledge) accumulation, and sharing, to name a few. The associated independent variables studied are trustworthiness, shared vision, strategic relatedness, absorptive capacity, centralization, formalization, geo- 
graphic distance, internal competition, and, more recently, divisional subculture. The dependent variables under investigation have been knowledge and information sharing, organization learning, time for new product development, innovation, and performance, to name a few (Gupta \& Govindrajan, 2000a; Hansen, 1999, 2002; Hansen \& Lovas, 2004; Hansen, Mors, \& Lovas, 2005; Marx, Lechner, \& Floyd, 2006; Powell, 2003; Skerlavaj \& Dimovski, 2006; Tsai, 2000, 2001, 2002; Tsai \& Ghoshal, 1998; Walter, Lechner, \& Kellerma, 2007).

More recently, Khoja and Maranville (2009) found that strong intra-firm networks enhance intellectual capital and that this relationship is further strengthened by absorptive capacity ${ }^{7}$. In addition, Hansen and Nohria (2004) posited that although firms can create value for themselves through inter-unit collaboration, they do need to overcome certain barriers by using a few 'management levers.' The barriers include units' '(I) unwillingness to seek input and learn from others, (2) inability to seek and find expertise, (3) unwillingness to help, and (4) inability to work together and transfer knowledge.' The management levers include 'leadership behavior, shared values and goals, human resource procedure, and lateral cross unit mechanisms.'

As organizational culture is the backbone of any organization and determines a firm's strategy and structure (Deal \& Kennedy, 1999), it becomes imperative to learn about the role culture plays in establishing social networks within organizations that is likely to assist units to collaborate, share, and exchange resources to attain competitive advantage. The research question addressed in this study is: 'how does strong organizational culture facilitate strong intra-firm networks?' In this paper, the inter-relationships among the 'management levers' of organizational culture that are depicted in their values, practices, and strong intrafirm ties are studied.

\section{Research Objectives}

The research objectives are to: (1) empirically test and extend existing line of research in the field of intra-firm networks, (2) highlight another plausible facet of organizational culture and its contribution in the prevalence of strong intra-firm networks, to help managers identify the benefits of the same, and (3) depict interdependencies among the values and practices of organizational cultural. The unit of analysis is a business unit, as the perspective of business heads and managers would truly depict the effectiveness of organizational culture.

In the following sections, the constructs of intra-firm networks and organizational culture are explicated. Hypotheses are then posited and Partial Least 
Square (PLS) technique is used to determine the results, followed by the discussion section.

\section{Theory}

The structural/content stream of research in the field of resource-based view states that the possession of key resources that may be rare or unavailable lead to firms' competitive advantage (Barney, 1991). The process/capability stream of the theory acknowledges that it is the utilization of resources or knowing capabilities in the development of new knowledge and competencies that lead to firms' competitive advantage (Lane, Koka, \& Pathak, 2006). As knowledge is considered to be one of the key resources (Grant, 1996), it is important to study how new knowledge can be developed and existing knowledge be nurtured within organizations. Empirical studies conducted by Khoja and Maranville (2009), Tsai (2001, 2002), and Tsai and Ghoshal (1998) have explicated how intra-firm networks can help organizations assimilate and integrate knowledge.

\section{Strong Intra-firm Networks}

Strong ties are associated with trust and exchange of fine-grained private knowledge but the information obtained through such network ties is likely to be redundant and, therefore, assumed not to be a channel for innovation (Burt, 1992). On the other hand, weak ties lead to novel but sparse information exchange resulting in increased innovation (Brass, et al., 2004; Hansen, 1999; Hansen, et al., 2005; McEvily \& Zaheer, 1999). Researchers have also argued that tie strength has a curvilinear impact on a host of dependent variables. Extremely strong and extremely weak ties provide diminished impact (Kraatz, 1998; Seibert, Kraimer, \& Liden, 2001). In other words, non-redundancy is a necessary but not a sufficient condition for acquisition of diverse information. Strong ties to these non-redundant contacts are also important to access closely held information and resources (Nicolaou \& Birley, 2003). More recently, Khoja and Maranville (2009) have argued that units are likely to develop and possess new knowledge that they share and exchange even when they are part of a strong network, contrary to the common belief that knowledge shared within strong networks is redundant (Brass, et al., 2004). 


\section{Organization Culture}

Organizational culture, though a ubiquitous phenomenon, is an intangible resource. In this study, both the conceptual and operational definitions of the construct are synthesized and hence, it is defined as shared perceptions of organizational values and practices within organizational units that both exemplify and reinforce the underlying assumptions and principles of an organization' (Denison, 1990; van den Berg \& Wilderom, 2004).

Researchers have argued that organizational cultural values and underlying assumptions are not as easily discernable as organizational practices or artifacts that are manifestations of the former (Singh, 2007; van den Berg \& Wilderom, 2004). Research has also demonstrated that organizations show more differences in practices than in values, and hence, claim practices to be more responsible for bringing about cultural change than cultural values (Hofstede, 2001). Thus, the relationships between organizational values and organizational practices are conjectured in this study.

Several recent studies have tabulated the varying dimensions of organizational culture (e.g. Detert, Schroeder, \& Mauriel, 2000; Tsui, Wang, \& Xin, 2006; van den Berg \& Wilderom, 2004) that show considerable similarity and overlap. However, after thorough literature review, consulting with academic experts, and rigorous pretesting, the various dimensions converged into five critical values and practices that are relevant to this study- task-orientation, risk-orientation, cooperation and practices of rewards (individual and collective), and open communication (Deal \& Kennedy, 1982, 1999; Detert, et al., 2000; Goffee \& Jones, 1996; Hofstede, 1998; Reynolds, 1986).

\section{Hypotheses}

In this section, the relationships between cultural values and strong intrafirm networks mediated by cultural practices are hypothesized.

\section{Practices: (i) Individual and Collective Rewards and (ii) Open Communication}

Units earn individual rewards when goals are achieved independently. Collective rewards are earned when units achieve their goals in collaboration with other units and hence, share the rewards based on their level of contribution. Both individual and collective rewards encourage units to grow independently as well as to share and co-develop resources to innovate and accomplish their objectives (Fedor 
\& Werther, 1995; Gibson \& Zelhur-Bruhn, 2001). Hence, these may be considered extrinsic forms of motivation that the organization partakes to foster participation from business units.

Through the practices of open communication such as encouraging regular face to face meeting and/or developing intranets, units can update and share their goals and achievements within the organization, signaling willingness to exchange resources and information. For instance, organizations can develop electronic yellow pages that list experts within the organization by area and provide benchmark systems that allow employees to identify best practices in the company (Hansen \& Nohria, 2004).

Task-orientation. This value focuses on organizational 'work' as an end in itself. The fundamental concern of task- oriented organizations is work accomplishment and productivity (Deal \& Kennedy, 1999; Detert, et al., 2000). In order to do so, units need to attain 'external knowledge' not resident within their own unit to fulfill tasks. It may be argued that units prefer to attain and assimilate information and knowledge from within the organization, whenever appropriate and available, as it is likely to reduce both appropriation and coordination costs (Gulati, 1998). The continuous need-based exchange and sharing within the organization may help build strong relationships within the same.

Risk-orientation. This predisposition allows units to change products or procedures, particularly when confronted with new challenges and opportunities (Deal \& Kennedy, 1982, 1999; Detert, et al., 2000; Gupta \& Govindrajan, 2000a; Peters \& Waterman, 1982; Reynolds, 1986). Organizations may encourage business units to be distinctive and idiosyncratic in their work contributions, thus creating a culture that values experimentation and innovation, which entails several risks and costs. By partnering and sharing intricate knowledge and information, business units not only dilute their risks and costs while hedging their bets, they are also able to access useful resources, that they themselves may lack, with minimum transaction costs (Hansen, et al., 2005), and in the process developing strong networks within the organization.

Cooperation. This is considered an engaging factor that successfully helps in the exchange, assimilation, and integration of knowledge, competencies, and capabilities for collective learning among business units (Deal \& Kennedy, 1999; Gupta \& Govindrajan, 2000a; Reagans \& McEvily, 2003), allowing the same to discuss initiatives and accomplishments (Gupta \& Govindrajan, 2000b; Storck \& Hill, 2000). Some organizations place a premium on relationship building as a means to better decision-making and overall output (Detert, et al., 2000) besides 
the added advantage of reduced appropriation and coordination costs incurred by the units.

\section{Relationship between Organizational Values and Strong Intra-firm Networks Mediated by Organizational Practices}

To fulfill tasks and to initiate experimentation in a timely and cost effective manner (Cross, Parker, Prusak, \& Borgartti, 2001), business units may feel the need for external knowledge and partners but due to internal rivalry (Khoja, 2008), "not-invented-here" (NIH) syndrome (Deal \& Kennedy, 1999), and/or threat of increased knowledge spillover, units might be hesitant to collaborate. However, organizational practices of collective rewards and open communication are likely to encourage business units to develop strong intra-firm networks and hence, attain common benefits (Khanna, Gulati \& Nohria, 1998). Common benefits accrue to each unit from the collective application of the learning that occurs as a consequence of being part of a relationship (Khanna, et al., 1998). On the other hand, units may be encouraged to form strong intra-firm networks by organizational offering of individual rewards to accomplish tasks and to experiment. Strong ties can assist units to tap into knowledge and informational database of other units and use it for their individual advantage, thus achieving private benefits of strong relationships. Private benefits are those that a unit can earn unilaterally by picking up skills and capabilities from its partners in a relationship and applying them to its own operations (Khanna, et al., 1998).

In short, units are likely to develop strong ties within the organizations to earn increased rewards (both individual and collective), as it may help units achieve their goals and objectives, as well as to share risks and costs of experimentation while innovating expeditiously. This may give units a competitive edge both within the organization and the industry. Hence, compliance with organizational values of task and risk orientation allows units to improve their chances of success whilst allowing them to receive more rewards. Hence,

Hypothesis la: The relationship between task-orientation and strong intrafirm networks is positively mediated by individual rewards.

Hypothesis 1b: The relationship between task-orientation and strong intrafirm networks is positively mediated by collective rewards.

Hypothesis 2a: The relationship between the risk-orientation and strong intra-firm networks is positively mediated by individual rewards. 
Hypothesis $2 \mathrm{~b}$ : The relationship between the risk-orientation and strong intra-firm networks is positively mediated by collective rewards.

It is further argued that due to dominant subcultures (Deal \& Kennedy, 1999) units are generally more unit-centered than organization-centered and are interested in accumulating more private benefits than common benefits from a relationship, consequently fostering cooperation and encouraging units to develop strong relationships by offering collective rewards and opportunities for open communication within the organization. Collective rewards provide the added incentive and open communication enhances ease and agility to share and exchange information and knowledge, hence favoring joint effort. Thus:

Hypothesis 3a: The relationship between the cooperative norm and strong intra-firm networks is positively mediated by collective rewards.

Hypothesis 3b: The relationship between the cooperative norm and strong intra-firm networks is positively mediated by open communication.

Figure 1

Hypothesized Model: Predictor, Criterion, and Mediation Relationships

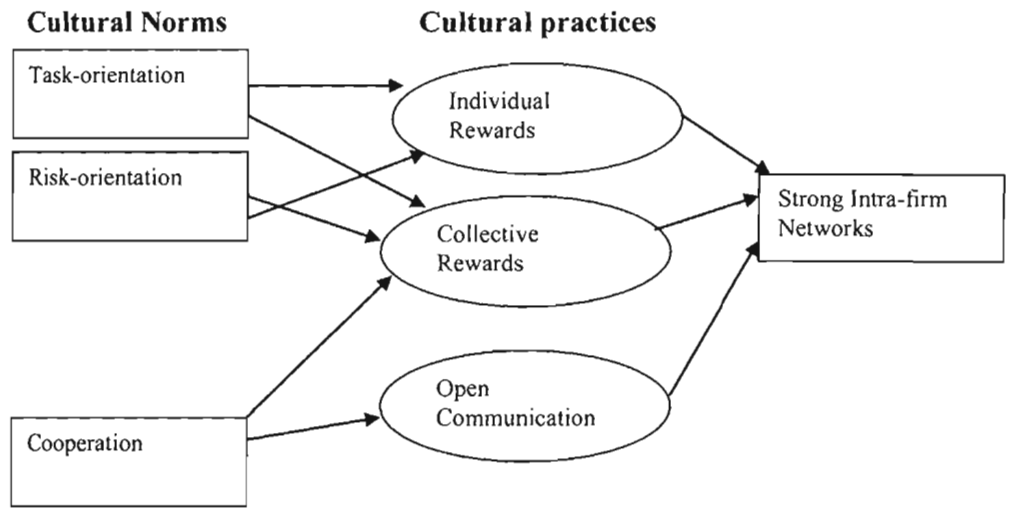

\section{Methodology}

"Company and Business Database" provides business and industry content bringing together company profiles, brand information, rankings, investment reports, company histories, chronologies, and journal articles. The sample was restricted to multi-divisional companies with at least 5 business units or divisions 
with revenues of above $\$ 500,000$ for the year 2000 . Surveys with a cover letter, a dollar bill, and a return envelope were mailed to 375 business unit heads (high level managers). The key informant approach has been successfully employed in several studies and high-level respondents are considered to be ideal candidates for such surveys (Rindfleisch \& Moorman, 2001), and to make certain, two questions on the survey confirmed their knowledge about the ongoing relationships with other business units within the organization and their involvement (Johnson, Sohi, \& Grewal, 2004). Although most high level managers were not involved in the formation of networks per se, they were found to be very knowledgeable of relationship activities.

\section{Sample}

In all, 75 surveys were returned out of which 74 could be used, giving a response rate of $23 \%$. Responses from varying divisions of 55 companies in 23 different industries were received. To test for non-response bias, differences between respondents and non-respondents were examined. A t-test showed no significant difference $(p<0.05)$ between the two groups based on the number of full-time employees and total sales and asset of the units.

To analyze the data, Partial Least Square technique (PLS) is used. It is a second-generation method of analysis with minimal demands on measurement scales, consisting as it does of a series of ordinary least-square analyses (Chin, 1998). The PLS technique focuses on predictor specification and on the variance of dependent variables. No assumptions are made regarding the joint distribution of the indicators or the independence of the sample cases. Because of its orientation to prediction, factors are determinate, and the unique case values of the latent variables are estimated (Chin, 1998; Chin \& Newsted, 1999). Recently, Shaver (2005) highlighted the discrepancies in standard tests for mediating relationships as proposed by Baron and Kenny (1986). He noted that violations of any of the assumptions on which the tests are built, such as uncorrelated error terms, mostly skew the estimates resulting in lack of desirable statistical properties that lead to incorrect conclusion. As the PLS technique makes no assumptions of joint distribution, the results of the mediating tests are less !ikely to be skewed, except for measurement error and missing variables.

The interpretation of the results generated by PLS is identical to that of traditional regression technique. Effect size or $\mathrm{R}^{2}$ for the endogenous variables of the measurement model and corresponding standardized path estimates are exam- 
ined and interpreted. To estimate the t-statistics for the weights and loadings of the indicators of the latent variables and the path coefficients of the measurement model, bootstrapping technique is used. Bootstrap represents a non-parametric approach where ' $n$ ' sample sets are created in order to obtain ' $n$ ' estimates of each parameter in the PLS model and is an effective tool to assess mediation in small samples (Shrout \& Bolger, 2002). To assess the internal consistency for a given block of indicators, composite reliability is calculated. In addition, average variance extracted (AVE) attempts to measure the amount of variance that a latent variable component captures from its indicators, relative to the amount due to measurement error.

All the constructs are measured using reflective items and with the exception of strong intra-firm networks, seven-point likert scale items adapted from previous literature and in consultation with academic experts. Strong intra-firm networks are measured using an interval items. In this study, factors of size, industry, and age of the units that reflect availability of organizational slack, experience, and industry volatility (Anand \& Khanna, 2000; Osborn \& Baugh, 1990; Tsai, 2001) are controlled for. Measurement items are provided in the Appendix.

\section{Results}

Table 1 shows the correlation matrix with the diagonals indicating the square root of average variance extracted (AVE) to check for discriminant validity, which ranges from 0.754 to 1.00 . The latent variables are seen to be distinct from each other, as they share more variance with their own block of indicators than with another component representing a different block of indicators.

Table 2 highlights the composite reliabilities and AVEs of independent latent variables. In general, the composite reliabilities range from 0.769 to 1.00 , indicating internal consistency of latent variables. AVE scores range from 0.568 to 1.00 , which explain reasonable variance shared among the latent variables and their respective block of indicators.

In this study, most of the dependent, independent, and mediating variables are moderately to highly correlated. Consequently, tolerance and variance inflation factor (VIF) are analyzed to test for multicollinearity. The results indicate that the minimum tolerance value from among all the latent variables was 0.7 and the maximum VIF value was 1.428 , which are well above and below the common threshold values of 0.19 and 5.3, respectively (Hair, Anderson, Tatham, \& Black, 1998). 
Table 1

Correlation Matrix ${ }^{\mathrm{a}}$

\begin{tabular}{|c|c|c|c|c|c|c|c|c|c|}
\hline Variables & 1 & 2 & 3 & 4 & 5 & 6 & 7 & 8 & 9 \\
\hline 1- intra-firm networks & 0.941 & & & & & & & & \\
\hline 2- Collective Rewards & $0.286^{\star \star}$ & 0.95 & & & & & & & \\
\hline 5- Individual Rewards & $0.375^{\star *}$ & $0.473^{\star \star \star}$ & 0.822 & & & & & & \\
\hline 6-Open Communication & $0.287^{\star \star}$ & $0.241^{*}$ & $0.552^{\star \star \star}$ & 0.754 & & & & & \\
\hline 7- Cooperative Norm & $0.331^{\star \star \star}$ & $0.770^{\star \star \star}$ & $0.598^{\star \star \star}$ & $0.222^{\star}$ & 0.932 & & & & \\
\hline 8- Task-Oriented Norm & $0.312^{* \star *}$ & $0.399^{* \star *}$ & $0.502^{\star \star \star}$ & 0.166 & $0.495^{\star \star \star}$ & 0.887 & & & \\
\hline 9- Risk-oriented Norm & $0.218^{* \star}$ & $0.62^{\star \star \star}$ & $0.484^{\star \star \star}$ & 0.175 & $0.641^{\star \star \star *}$ & $0.612^{\star \star *}$ & 0.815 & & \\
\hline 10- Size & 0.089 & $0.271^{*}$ & -0.154 & 0.089 & 0.143 & 0.098 & -0.191 & 1.00 & \\
\hline 12- Age & -0.052 & 0.003 & -0.061 & -0.093 & 0.003 & 0.116 & $0.423^{\star \star \star}$ & $0.297^{\star \star}$ & 1.00 \\
\hline
\end{tabular}

${ }^{a} n=74$. Standardized coefficients indicating two-tailed significance.

${ }^{*} p<0.5 ;{ }^{* *} p<0.01 ;{ }^{* * *} p<0.005$ 
Table 2

Composite Reliabilities and Average Variance Extracted (AVEs) of Latent Variables

\begin{tabular}{lcc}
\hline Varlables & Composite Reliabilities & AVE \\
\hline Strong intra-firm networks & 0.939 & 0.885 \\
Collective Rewards & 0.947 & 0.912 \\
Individual Rewards & 0.804 & 0.676 \\
Open Communication & 0.769 & 0.568 \\
Cooperative norm & 0.952 & 0.869 \\
Task-oriented norm & 0.917 & 0.787 \\
Risk-oriented norm & 0.855 & 0.664 \\
Size & 1.00 & 1.00 \\
Age & 1.00 & 1.00 \\
\hline
\end{tabular}

Modest composite reliability $=0.7$

Modest AVE score $=0.5$

\section{Mediating Relationships}

Hypotheses $1 \mathrm{a}$ and $\mathrm{lb}$ are fully supported as the magnitude and strength of the direct relationship between task-orientation and strong intra-firm networks $\left(\beta_{1}=0.337, p<0.005\right)$ is completely mediated by practices of individual and collective rewards $\left(\beta_{\mathrm{la}}=0.135\right.$, n.s.) and $\left(\beta_{\mathrm{lb}}=0.210\right.$, n.s.). Task orientation strongly impacts individual rewards $\left(\beta_{\mathrm{la}}=0.537, \mathrm{p}<0.005\right)$, which in turn significantly influences strong intra-firm networks $\left(\beta_{1 \mathrm{a}}=0.352, \mathrm{p}<0.005\right)$. Task orientation also influences collective rewards $\left(\beta_{\mathrm{tb}}=0.517, \mathrm{p}<0.005\right)$, which in turn impacts strong intra-firm networks $\left(\beta_{1 b}=0.212, p<0.05\right)$. The $\mathrm{R}^{2}$ for the direct relationship is 0.13 , explaining $13 \%$ variance and for the indirect relationships, 0.203 and 0.156 , respectively.

Hypotheses $2 \mathrm{a}$ and $2 \mathrm{~b}$ are also fully supported as the strong relationship existent between risk-orientation and intra-firm networks $\left(\beta_{2}=0.238, p<0.005\right)$ is completely mediated by individual and collective rewards $\left(\beta_{2 \mathrm{a}}=0.029\right.$, n.s. $)$ and $\left(\beta_{2 b}=0.06\right.$, n.s. $)$. Risk orientation strongly impacts individual rewards $\left(\beta_{2 \mathrm{a}}=0.504\right.$, $\mathrm{p}<0.005)$, which in turn significantly influences strong intra-firm networks $\left(\beta_{2 \mathrm{a}}=\right.$ $0.405, p<0.005)$. Risk orientation also influences collective rewards $\left(\beta_{2 b}=0.636, p\right.$ $<0.005)$, which in turn impacts strong intra-firm networks $\left(\beta_{2 b}=0.281, p<0.05\right)$. The $\mathrm{R}^{2}$ for the direct relationship is 0.071 , explaining $7.1 \%$ variance and for the indirect relationships, 0.187 and 0.125 , respectively. 
Both hypotheses $3 \mathrm{a}$ and $3 \mathrm{~b}$ are not supported, as the direct relationship between cooperation and strong intra-firm networks $\left(\beta_{3}=0.304, p<0.005\right)$ is not mediated by either collective rewards $\left(\beta_{3 \mathrm{a}}=0.323, \mathrm{p}<0.005\right)$ or open communication $\left(\beta_{3 \mathrm{~b}}=0.250, \mathrm{p}<0.05\right)$. Collective rewards do not significantly impact strong intra-firm networks ( $\beta_{3 \mathrm{a}}=0.076$, n.s.), although the relationship between cooperation and collective rewards is significant $\left(\beta_{3 \mathrm{a}}=0.773, \mathrm{p}<0.005\right)$. Similarly, cooperative norm significantly influences open communication $\left(\beta_{3 \mathrm{~b}}=0.523, \mathrm{p}<0.005\right)$, but does not significantly impact strong intra-firm networks $\left(\beta_{3 b}=0.224\right.$, n.s.). The $\mathrm{R}^{2}$ for the direct relationship is 0.159 , explaining $15.9 \%$ variance and for the indirect relationships are 0.16 and 0.173 , respectively. Tables 3 summarize the hypothesized measurement models.

\section{Discussion}

Strong relationships are the "grease" of any organization (Prusak, 1997). Business gets done without them, but not for long and not very well. The mediating relationships between organizational values and organizational practices depict that the values instilled within the organization would not be effective if they were not followed by practices fostering them. For example, by encouraging business units to accomplish tasks in a timely manner and experimenting creatively, units are likely to obtain help from other sister business units that are culturally regulated and are less likely to behave opportunistically than partners outside of the organization. However, units are likely to build relationships to fulfill their tasks and risk-taking activities if cultural practices, such as open communication and rewards incentivize them sufficiently to do so. It is found that cooperative values indigenously motivate units to develop strong networks and do not require the added inducement of collective rewards or open communication, as these practices seem to be resonant in values of cooperation.

Theoretical, empirical, and practical contributions to the existing strategic management literature and to social network research, in particular, are discussed in the following section.

\section{Theoretical Contributions}

In this study, the inter-related role of organizational cultural values and practices, and strong intra-firm networks are emphasized and evaluated. The study suggests that organizational culture instills within an organization the values, norms, and beliefs that help the organizations facilitate strong social intra-firm networks. 
Table 3

The Interrelationships among Organizational Values, Practices and Strong Intra-firm Networks ${ }^{\mathrm{a}}$

\section{Dependent Variable- Strong Intra-firm Networks}

\begin{tabular}{|c|c|c|c|c|c|c|c|c|c|c|}
\hline \multicolumn{11}{|l|}{ Control Variables } \\
\hline Age & -0.002 & -0.038 & 0.011 & 0.019 & -0.024 & -0.026 & -0.01 & -0.008 & 0.013 & 0.029 \\
\hline Size & -0.125 & -0.001 & -0.10 & -0.007 & -0.067 & -0.109 & -0.073 & -0.131 & -0.005 & -0.10 \\
\hline industry & 0.094 & 0.076 & 0.08 & 0.099 & 0.074 & 0.065 & 0.077 & 0.062 & 0.089 & 0.101 \\
\hline \multicolumn{11}{|l|}{ Independent Variables } \\
\hline Task-oriented norm & & $0.337^{\star \star *}$ & & & 0.135 & 0.210 & & & & \\
\hline Risk-oriented norm & & & $0.238^{\star *}$ & & & & 0.029 & 0.061 & & \\
\hline Cooperative norm & & & & $0.304^{\star \star \star}$ & & & & & $0.323^{\star \star \star}$ & $0.25^{*}$ \\
\hline Individual rewards & & & & & $0.352^{* * *}$ & & $0.405^{\star \star \star}$ & & & \\
\hline Collective rewards & & & & & & $0.212^{*}$ & & $0.281^{\star \star}$ & 0.076 & \\
\hline Open communication & & & & & & & & & & 0.176 \\
\hline$R^{2}$ & 0.029 & 0.130 & 0.071 & 0.159 & 0.203 & 0.156 & 0.125 & 0.187 & 0.160 & 0.173 \\
\hline Effect size - f2 & & 0.131 & 0.05 & 0.155 & 0.22 & 0.15 & 0.11 & 0.194 & 0.156 & 0.174 \\
\hline$d f$ & 3,71 & 4,70 & 4,70 & 4,70 & 5,69 & 5,69 & 5,69 & 5,69 & 5,69 & 5,69 \\
\hline
\end{tabular}

${ }^{a} \mathrm{n}=74$

${ }^{\star} p<0.5 ;{ }^{* \star} p<0.01 ;{ }^{* \star \star} p<0.005$ 
The dynamic view of social intra-firm network is discussed as it relates to the formation and development of networks through the organizational practices that are implemented within the organization. To some extent, it involves the evolution of strong intra-firm networks and a change in the overall functioning and structure of the organization.

\section{Empirical Contributions}

Little empirical work has been conducted in the field of social intra-firm networks or intra-organizational linkages (Brass, et al., 2004), and researchers have commonly used it as a relational construct in one-site sampling scheme to test their hypotheses (Gupta \& Govindrajan, 2000b; Hansen, 1999; Tsai, 2000, 2001; Tsai \& Ghoshal, 1998). Furthermore, very few studies have analyzed the antecedents of intra-firm networks in detail (Hansen \& Lovas, 2004; Tsai \& Ghoshal, 1998; Tsai, 2002; Walter, et al., 2007). In this study, the findings are justified by administering a survey on a sample of business units from different organizations in various industries using likert scale measures. Hence, shifting gears from simple binary considerations, such as the existence or non-existence of relationships to the importance and strength of the relationships (Brass, et al., 2004). Use of multiple sites also enhance generalizability and reinforce validity for the theoretical model (Gupta \& Govindrajan, 1984).

\section{Practical Contributions}

Several practical implications can also be drawn from this. First, this research highlights the necessity of management levers such as organizational values and goals, human resource practices of reward structures, and cross unit mechanisms for open communication to enhance relationship development within organizations. In an era when advantages based on traditional economies of scope and scale are rapidly diminishing, the successful exploitation of strong relationships may hold the key for organizations to gain and maintain lead over their rivals.

Organizational culture plays an important role in establishing an organization's identity by giving it value, direction, and purpose in order to increase performance as well as enable firms to adapt to external environmental conditions (Goffee \& Jones, 1996; Tsui, et al., 2006). This research highlights the important role organizational culture plays in building organization character and backbone by helping units achieve their potential and objectives by encouraging development of strong intra-firm networks. Practices appear to have a more direct impact on orga- 
nizational values and support the same. Thus, managers should be vigilant to steer cultural values and practices to guide units and help them be successful.

\section{Limitations}

While this research study advances the understanding of the development and role of social intra-firm networks, it is not without its limitations. First, only a few cultural values and practices that facilitate the promotion of social intrafirm networks are employed in this study, which does not necessarily portray the complete picture. Second, in this study, cultural variables are measured through the lens of the business unit heads or managers and results may be influenced by the subcultures of individual business units. Most likely because of the dominant subcultures that may overshadow organizational culture, some confounding results may be apparent when testing the mediating role of intra-firm networks. In addition, geographic proximity, that may influence the ease of reluctance to develop intrafirm networks is not taken into account (Gansen, Malter \& Rindfleisch, 2005; Singh, 2005). Lastly, due to subjective reporting of all the variables by a single respondent, business unit heads, or managers, measurement error and common method variance can be seen as another limitation of this study (Collins \& Clark, 2003).

\section{Future Research}

This line of research can be developed further to make significant contributions to the existing literature on social intra-firm networks. Future research should focus on collecting longitudinal data to test the predictive relationships between the independent and mediating variables measured above. This would allow researchers to analyze the changes within organizations in both volatile and stable markets and economic conditions. Furthermore, other predictor variables that influence the development of social intra-firm networks, such as resource requirements and organizational structures can be studied, in addition to the consequences of the same, for example, objective and strategic performance.

The extant literature on both inter-organizational and intra-organizational relationships has determined the advantages and disadvantages of cach independently, and hence, they could be studied together to compare which one is more favorable than another. Also, previous literature has stressed the importance of informal networks for purposes of knowledge accumulation, sharing and exchanging resources, etc. Research can compare formal and informal networks to ascertain 
the significance of each and their potential to tap into the tangible and intangible resources within the organization.

\section{Conclusion}

This research study attains the primary objective of this study by empirically testing the relationship between organizational cultural values and practices and strong intra-firm networks. The results indicate that cultural values of task and riskorientation are positively related to strong intra-firm networks and these relationships are mediated by practices of open communication and individual and collective rewards. Strong association between cooperative norms and strong intra-firm networks is not mediated by any of the cultural practices.

\section{End Notes}

1. Relationships with other business units within organization (Tsai \& Ghoshal, 1998)

2. A central informational and/or control central position in a network (Tsai, 2001)

3. Non-redundnat contacts (Burt, 1992)

4. Bonding among business units (Granovetter, 1973)

5. Number of units constituting a network (Gulati, 1998)

6. Number of ties per unit (Coleman, 1988)

7. Capability to acquire and assimilate new knowledge gained from other sources (Lane \& Lubatkin, 1998; Tsai, 2001).

\section{References}

Achrol, R., \& Kotler, P. (1999). Marketing in the network economy. Journal of Marketing, 63, 146-163.

Ahuja, G. (2000). The duality of collaboration: Inducements and opportunities in the formation of inter-firm linkages. Strategic Management Journal, 2l(3), 317344.

Anand, B., \& Khanna, T. (2000). Do firms learn to create value? The case of alliances [Special Issue]. Strategic Management Journal, 2l(3), 295-315.

Barney, J. (1991). Firm resources and sustained competitive advantage. Journal of Management, 17, 99-120. 
Baron, R., \& Kenny, D. (1986). The moderator-mediator variable distinction in social psychological research: Conceptual, strategic, and statistical considerations. Journal of Personality and Social Psychology, 5I(6), 1173-1182.

Brass, D., Galaskiewicz, J., Greve, H., \& Tsai, W. (2004). Taking stock of networks and organizations: A multi-level perspective. Academy of Management Journal, 7(6), 795-819.

Burt, R. (1992). Structural holes: The social structure of competition. Cambridge, MA: Harvard University Press.

Chin, W. (1998). The partial least squares approach of structural equations modeling. In G. A. Marcoulides (Ed.), Modern methods for business research (pp. 295-336). Mahwah, NJ: Lawrence Erlbaum Associates, Publishers.

Chin, W., \& Newsted, P. (1999). Structural equations modeling analysis with small samples using partial least squares. In R. Hoyle (Ed.), Statistical strategies in small sample research (pp. 307-34I). Thousand Oaks, CA: Sage Publishers.

Collins, C., \& Clark, K. (2003). Strategic management resource practices, top management team, social networks and firm performance: The role of human resource practices in creating organizational competitive advantage. Academy of Management Journal, 46(6), 740-752.

Cross, R., Parker, A., Prusak, L., \& Borgatti, S. (2001). Knowing what we know: Supporting knowledge creation and sharing in social networks. Organizational Dynamics, 30(2), 100-120.

Deal, T., \& Kennedy, A. (1982). Corporate culture. Reading, MA: Addison-Wesley.

Deal, T., \& Kennedy, A. (1999). The new corporate cultures: Revitalizing the workplace after downsizing, mergers and reengineering. Reading, MA: Peruses Books.

Denison, D. (1990). Corporate culture and organizational effectiveness. New York: Wiley \& Associates.

Detert, J., Schroeder, R., \& Mauriel, J. (2000). A framework for linking culture and improvement initiatives in organizations. Academy of Management Review, $25(4), 850-863$.

Fedor, K. \& Werther, W. (1995). Making sense of cultural factors in international alliances. Organization Dynamics, 23(4), 33-49.

Ganeson, S., Malter, A., \& Rindfleisch, A. (2005). Does distance still matter? Geographic proximity and new product development. Journal of Marketing, 69, 44-60.

Gibson, C., \& Zellmer-Bruhn, M. (2001). Metaphors and meaning: An intercultural analysis of the concept of teamwork. Administrative Science Quarterly, 46(2), 274-304. 
Goffee, R., \& Jones, G. (1996, November-December). What holds the modern company together? Harvard Business Review, 133-148.

Granovetter, M. (1973). The strength of weak ties. American Journal of Sociology, $78,1360-1380$.

Grant, R. (1996). Toward knowledge based theory of the firm [Special issue]. Strategic Management Journal, 27, 109-122.

Gulati, R. (1998). Alliances and networks. Strategic Management Journal, 19, 293 317.

Gulati, R., \& Singh, H. (1998). The architecture of cooperation: Managing coordination costs and appropriation concerns in strategic alliances. Administrative Science Quarterly, 43(4), 781-814.

Gupta, A., \& Govindrajan, V. (1984). Business unit strategy, managerial characteristics, and business unit effectiveness at strategy implementation. Academy of Management Journal, 27, 25-41.

Gupta, A., \& Govindrajan, V. (2000a). Knowledge management's social dimension: Lessons from Nucor steel. Sloan Management Review, 42(1), 71-80.

Gupta, A., \& Govindrajan, V. (2000b). Knowledge flows within multinational corporations. Strategic Management Journal, 2l(4), 473-496.

Hair, J., Anderson, R., Tatham, R., \& Black, W. (1998). Multivariate data analysis (5th ed.). Upper Saddle River, NJ: Prentice Hall.

Hansen, M. (1999). The search-transfer problem: The role of weak ties in sharing knowledge across organization subunits. Administrative Science Quarterly, 44(1), 82-111.

Hansen, M. (2002). Knowledge networks: Explaining effective knowledge sharing in multiunit companies. Organization Science, 13(3), 232-248.

Hansen, M., \& Lovas B. (2004). How do multinational companies leverage technological competencies? Moving from single to interdependent explanations. Strategic Management Journal, 25, 801-822.

Hansen, M., \& Mors, M., Lovas, B. (2005). Knowledge sharing in organizations: Multiple networks, multiple phases. Academy of Management Journal, 48(5), 776-793.

Hansen, M., \& Nohria, N. (2004, Fall). How to build collaborative advantage. MIT Sloan Management Review, 21-30.

Hofstede, G. (1998). Attitudes, values and organizational culture: Disentangling the concepts. Organization Studies, 19(3), 477-492.

Hofstede, G. (2001). Culture's consequences: Comparing values, behaviors, institutions, and organizations across nations. Thousand Oaks, CA: Sage Publishers. 
Johnson, J., Sohi, R., \& Grewal, R. (2004). The role of relational knowledge stores in interfirm partnering. Journal of Marketing, 66, 21-36.

Khanna, T., Gulati, R., \& Nohria, N. (1998). The dynamics of learning alliances: Competition, cooperation and relative scope. Strategic Management Journal, 19, 193-200.

Khoja, F. (2008). Is sibling rivalry good or bad for high technology organizations? Journal of High Technology Management Research, 19(1), 11-20.

Khoja, F., \& Maranville, S. (2009). The power of social intra-firm networks. Academy of Strategic Management Journal, 8, 51-70.

Kraatz, M. (1998). Learning by association? Inter-organizational networks and adaptation to environmental change. Academy of Management Journal, 41, 621643.

Lane, P., Koka, B., \& Pathak, S. (2006). The Reification of absorptive capacity: A critical review and rejuvenation of the construct. Academy of Management Review, 31(4), 833-863.

Lane, P. J., \& Lubatkin, M. (1998). Relative absorptive capacity and inter-organizational learning. Strategic Management Journal, 19, 461-477.

Marx, K., Lechner, C., \& Floyd, S. (2006). Intrafirm networks and the performance of strategic initiatives. Academy of Management Best Conference Paper BPS: SSl.

McEvily, B., \& Zaheer, A. (1999). Bridging ties: A source of firm heterogeneity in competitive capabilities. Strategic Management Journal, 20, 1133-I156.

Nicolaou, N., \& Birley, S. (2003). Social networks in organizational emergence: The university spinout phenomenon. Management Science, 49(12), 1702-1725.

Nohria, N., \& Eccles, R. (1992). Face-to-face: Making network organizations work. In N. Nohria \& R. G. Eccles (Eds.), Network and organizations: Structure, form and action (pp. 288-308). Boston: Harvard Business School Press.

Osborn, R., \& Baugh, C. (1990). Forms of inter-organizational governance for multinational alliances. Academy of Management Journal, 33(3), 503-519.

Peters, T., \& Waterman, R. (1982). In search of excellence: Lessons from America's best run companies. New York: Harper and Row.

Powell, T. (2003). Information sharing and its link to organizational sub-cultures in a manufacturing company. Journal of Applied Business Research, 19(2), 67-75.

Prusak, S. (1997, September-October). Unleashing the power of learning. An interview with British Petroleum's John Browne. Harvard Business Review, 147-168. 
Reagans, R., \& McEvily, B. (2003). Network structure and knowledge transfer: The effects of cohesion and range. Administrative Science Quarterly, 48(2), 240268.

Reynolds, P. (1986). Organizational culture as related to industry, position and performance: A preliminary report. Journal of Management Studies, 23(3), 333345.

Rindfleisch, A., \& Moorman, C. (2001). The acquisition and utilization of information in new product alliances: Strength of ties perspective. Journal of Marketing, 65(2), 1-18.

Seibert, S., Kraimer, M., \& Liden, R. (2001). A social capital theory of career success. Academy of Management Journal, 44(2), 219-237.

Shaver, J. (2005). Testing for mediating variables in management research: Concerns, implications, and alternative strategies. Journal of Management, 31(3), 330- 353 .

Shrout, P., \& Bolger, N. (2002). Mediation in experimental and non-experimental studies: New procedures and recommendations. Psychological Methods, 7(4), 422-445.

Singh, J. (2005). Collaborative networks as determinants of knowledge diffusion patterns. Management Science, 5I(5), 756-770.

Singh, K. (2007). Predicting organizational commitment through organization culture: A study of automobile industry in India. Journal of Business Economics and Management, 8(1), 29-37.

Skerlavaj, M., \& Dimovski, V. (2006). Social network approach to organizational learning. Journal of Applied Business Research, 22(2), 89-97.

Storck, J., \& Hill, P. (2000). Knowledge diffusion through 'strategic communities.' Sloan Management Review, 4I(2), 63-75.

Tsai, W. (2000). Social capital, strategic relatedness and the formation of intra-organizational linkages. Strategic Management Journal, 21, 925-939.

Tsai, W. (2001). Knowledge transfer in intra-organizational networks: Effects of network position and absorptive capacity on business unit innovation and performance. Academy of Management Journal, 44(5), 996-1017.

Tsai, W. (2002). Social structure of cooptation within a multiunit organization: Coordination, competition and intra-organizational knowledge sharing. Organization Science, 13(2), 179-190.

Tsai, W., \& Ghoshal, S. (1998). Social capital and value creation: The role of intrafirm networks. Academy of Management Journal, 4l(4), 464-476. 
Tsui, A., Wang, H., \& Xin, K. (2006). Organizational culture in China: An analysis of culture dimensions and culture types. Management and Organization Review, 2(3), 345-376.

Van den Berg, P., \& Wilderom, C. (2004). Defining, measuring and comparing organizational culture. Applied Psychology: An International Review, 53(4), 57-582.

Walter, J., Lechner, C., \& Kellermanns, F. (2007). Knowledge transfer between and within alliance partners: Private versus collective benefits of social capital. Journal of Business Research, 60, 698-710. 


\section{Appendix}

Organizational Culture is defined as "the shared philosophies, ideologies, values, assumptions, beliefs, expectations, attitudes and norms that knit a community together" (Szilagyi \& Wallace, 1990: 639).

Organizational Values (Adopted from Deal \& Kennedy, 1982; Reynolds, 1986).

\section{Task-orientation}

1. Our company places emphasis on improving work methods within business units.

Strongly Disagree 1

2

4 5

Strongly Agree

$6 \quad 7$

2. Our company places emphasis on maintaining high standards of performance for business units.

Strongly Disagree

3

4

5

$6 \quad 7$

Strongly Agree

3. Our company places emphasis on setting specific goals and achieving them.

Strongly Disagree

12

2

34

5

Strongly Agree

$6 \quad 7$

\section{Risk-orientation}

1. Our company is receptive to new ideas and suggestions coming from business units.

Strongly Disagree 1

$\begin{array}{lll}2 & 3 & 4\end{array}$

45

Strongly Agree

2. Our company allows the business units to be creative and innovative.

Strongly Disagree

1

23

45

5

Strongly Agree

3. Our company encourages business units to learn new competencies and new skills.

Strongly Disagree

1

23

4

5

Strongly Agree

Cooperation

1. Our company encourages business units to work together.

Strongly Disagree

12

2

3

4

5

Strongly Agree

2. Our company encourages cooperation within business units.

Strongly Disagree

$\begin{array}{llll}2 & 3 & 4 & 5\end{array}$

Strongly Agree

67

3. Our company encourages business units to help out each other.

Strongly Disagree

$\begin{array}{ccccccc}1 & 2 & 3 & 4 & 5 & 6 & 7\end{array}$


Organizational Practices (Adopted from Deal \& Kennedy, 1982; Reynolds, 1986).

\section{Collective Rewards}

1. Our company rewards business units adequately for working with other business units within the company.

$\begin{array}{cccccccc}\text { Strongly Disagree } & & & & & \text { Strongly Agree } \\ 1 & 2 & 3 & 4 & 5 & 6 & 7\end{array}$

2. Our company rewards business units for their collective efforts with each other.

Strongly Disagree

$$
12
$$

23

4

5

Strongly Agree

Individual Rewards

1. Our company rewards business units rewards businesses for achieving our goals.

Strongly Disagree

2

3

4

5

$6 \quad 7$

67

2. Our company provides additional resources when our business unit achieves its goals.

Strongly Disagree

1

23

4

5

Strongly Agree

\section{Open Communication}

1. Our company holds meetings regularly where business units discuss their goals and achievements.

$\begin{array}{cccccccc}\text { Strongly Disagree } & & & & & & \text { Strongly Agree } \\ 1 & 2 & 3 & 4 & 5 & 6 & 7\end{array}$

2. Our company encourages business units to share information with each other over the intranet.

Strongly Disagree

$\begin{array}{lllllll}1 & 2 & 3 & 4 & 5 & 6 & 7\end{array}$

3. Our company encourages face-to-face communication.

Strongly Disagree

1

2

$3 \quad 4$

5

Strongly Agree

$6 \quad 7$

Intrafirm Networks defined as 'a set of formal and/or informal relationships among business units of the same legal entity'

Over all, internal network relationships are:

$\begin{array}{ccccccc}\text { Extremely weak } & & \text { Neutral } & \text { Extremely strong } \\ -3 & -2 & -1 & 0 & 1 & 2 & 3 \\ \text { Poor } & & & \text { Neutral } \\ -3 & -2 & -1 & 0 & 1 & 2 & 3\end{array}$

\section{Controls}

Size (Adapted from Tsai, 2001)

Number of employees working in our business unit is:

Industry

Use dummy coding for 24 industries (n-1)

Age

When was your unit established? 


\section{Biographical Sketch of Author}

Faiza Khoja, Ph.D. is an Associate Professor of Management at University of Houston-Downtown, College of Business. She earned her Ph.D. from University of Houston in Strategic Management and her research interests are in the areas of social networks, intra-firm competition, buyer-supplier relationships, and developmental economics. She primarily teaches strategic management in addition to international management. 